\title{
EMERGÊnCIA De Tridax procumbens em FunçÃo da Profundidade de Semeadura, do Conteúdo de ARGila no Substrato e da InCidênCIA DE LUZ NA SEMENTE ${ }^{1}$
}

\author{
Tridax procumbens Emergence as a Function of Sowing Depth, Substrate Clay Content and \\ Light Incidence
}

GUIMARÃES, S.C. ${ }^{2}$, SOUZA, I.F. ${ }^{3}$ e PINHO, E.V.R.V. ${ }^{3}$

\begin{abstract}
RESUMO - Os solos agrícolas possuem banco de sementes de plantas daninhas cuja quantidade varia de dezenas a centenas de milhões de sementes por hectare, as quais são dotadas de mecanismos para detectar o tempo e o local apropriado para a germinação. A profundidade no solo em que uma semente é capaz de germinar e produzir plântula é variável entre as espécies e apresenta importância ecológica e agronômica. Com o objetivo de estudar a emergência de plântulas de erva-de-touro (Tridax procumbens), em função da profundidade de semeadura, do conteúdo de argila no substrato e do tratamento de sementes com luz, foram realizados dois experimentos no Departamento de Agricultura da Universidade Federal de Lavras. No experimento 1, a emergência das plântulas foi avaliada em vasos contendo substrato com $60 \%$ de argila, com semeadura realizada nas profundidades de $1,2,3,4,5$ e $6 \mathrm{~cm}$, e também com aquênios parcialmente enterrados (APE). No experimento 2, foram utilizadas sementes com e sem tratamento para superação da necessidade de luz (embebição por 48 horas em GA $1 \mathrm{mmol} \mathrm{L}^{-1}+\mathrm{KNO}_{3} 25 \mathrm{mmol} \mathrm{L}^{-1}+\mathrm{luz}$ ), semeadas em substratos com 30 e $60 \%$ de argila, a $1 \mathrm{~cm}, 2 \mathrm{~cm}$ e APE, e também em areia a $3 \mathrm{~cm}$. A emergência das plântulas de erva-de-touro foi máxima quando os aquênios foram parcialmente enterrados no substrato, independentemente do conteúdo de argila deste. Em profundidades maiores ou iguais a $1 \mathrm{~cm}$ houve drástica redução na emergência, que foi nula (experimento 2) ou quase nula (experimento 1) a $3 \mathrm{~cm}$. O tratamento para superação da necessidade de luz aumentou a emergência nas semeaduras a 1 e a $2 \mathrm{~cm}$, mas não teve efeito a $3 \mathrm{~cm}$.
\end{abstract}

Palavras-chave: erva-de-touro, planta daninha, germinação, ácido giberélico, nitrato.

\begin{abstract}
Agricultural soils may contain weed seedbanks of hundreds of millions of weed seeds per hectare, which have mechanisms to detect the appropriate time and place for germination. The soil depth in which a seed is capable of germinating varies among species, presenting ecological and agronomic importance. With the objective of studying Tridax procumbens seedling emergence as a function of sowing depth, substrate clay content, and seed treatment to overcome light requirement, two experiments were carried out at the Department of Agriculture of the University of Lavras - Brazil. In experiment 1, seedling emergence was evaluated in pots containing a 60\% clay substrate, at sowing depths of 1, 2, 3, 4, 5 and $6 \mathrm{~cm}$, and also with the partially buried achenes (PBA). In experiment 2, seeds with or without light overcoming treatment were used (imbibition for 48 hours in $\mathrm{GA}_{3} 1 \mathrm{mmol} \mathrm{L}^{-1}+\mathrm{KNO}_{3} 25 \mathrm{mmol} \mathrm{L}^{-1}$ + light), sown in substrates with 30 and 60\% clay, at the depth of $1 \mathrm{~cm}, 2 \mathrm{~cm}$ and PBA, and also in sand at $3 \mathrm{~cm}$ depth. Tridax procumbens seedling emergence was greatest when the achenes were partially buried in the substrate, regardless of its clay content. There was a great reduction in emergence at depths higher and lower than $1 \mathrm{~cm}$, which was null (experiment 2) and almost null (experiment 1) at $3 \mathrm{~cm}$ depth. Treatment to overcome light requirement improved emergence at sowing depths of 1 and $2 \mathrm{~cm}$, but was ineffective at $3 \mathrm{~cm}$ sowing depth.
\end{abstract}

Key words: coat button, weed, germination, gibberellic acid, nitrate.

Recebido para publicação em 3/10/2001 e na forma revisada em 9/12/2002.

Prof. da Universidade Federal de Mato Grosso - UFMT/FAMEV/DFF, 78060-900 Cuiabá-MT. ${ }^{3}$ Prof. da Universidade Federal de Lavras - UFLA/DAG, 37200-000 Lavras-MG.

Planta Daninha, Viçosa-MG, v.20, n.3, p.413-419, 2002 


\section{INTRODUÇÃO}

Uma das maiores limitações para se implementar um programa de manejo de plantas daninhas é a falta de conhecimentos sobre a biologia e ecologia das espécies (Fernandez, 1982). Nos ambientes agrícolas constantemente perturbados, a formação da comunidade de plantas daninhas depende do estabelecimento periódico das plântulas, com base na germinação das sementes presentes no solo (banco de sementes), e a composição específica e a densidade dependem, entre outros fatores, do tamanho do banco de sementes, das condições climáticas e da distribuição dessas sementes no perfil do solo (Carmona, 1992; Dyer, 1995).

Grande parte das plantas daninhas evoluiu para a produção de elevado número de sementes, em detrimento de seu tamanho (Holzner et al., 1982), apresentando assim mecanismos para evitar a germinação em profundidades inadequadas no solo, já que a pequena disponibilidade de reservas não seria suficiente para suportar o crescimento da plântula até a emergência (Bewley \& Black, 1994). Em algumas espécies, como Stachytarpheta cayennensis (Dias Filho, 1996), as sementes somente germinam na superfície ou nos primeiros milímetros do solo, embora em outras elas sejam capazes de germinar e produzir plântulas em profundidades de até $10 \mathrm{~cm}$, como em Ipomoea asarifolia (Dias Filho, 1996), ou às vezes superiores a $15 \mathrm{~cm}$, como em Xanthium strumarium (Toledo et al., 1993). Essa capacidade de germinar ou não em maiores profundidades pode determinar as espécies que irão predominar nos diferentes sistemas de produção, em função principalmente dos métodos de adequação das áreas para o plantio. Os métodos de preparo afetam de modo diferenciado a distribuição das sementes no perfil do solo, influenciando a germinação e a formação da comunidade infestante. Por isso, torna-se relevante conhecer o potencial de produção de plântulas, a diferentes profundidades de semeadura, como elemento adicional para o entendimento da dinâmica das populações, necessário para a melhoria da eficácia das táticas de manejo.

De importância recente para o Brasil, a planta daninha erva-de-touro (Tridax procumbens) é pouco estudada. Pelo fato de possuir sementes pequenas, com massa dos aquênios variando de 0,64 a 0,68 mg (Guimarães et al., 2000a), e também fotoblásticas positivas (Popay, 1974; Marks \& Akosim, 1984), espera-se que a emergência de plântulas nessa espécie só ocorra a partir de diásporos posicionados nas camadas superficiais do solo. No entanto, no trabalho de Sharma (1987), embora tenha ocorrido maior porcentagem de plântulas quando os aquênios de erva-de-touro foram colocados na superfície, houve emergências em semeaduras até $5 \mathrm{~cm}$ de profundidade, informação surpreendente considerando-se a pequena massa das sementes. Também, nesse trabalho, as emergências em semeaduras a 1 e a $2 \mathrm{~cm}$ foram superiores à germinação verificada no escuro, indicando que a necessidade de luz para a germinação pode ter sido superada nesse ambiente, uma vez que os comprimentos de onda para ativação do processo germinativo só penetram nos primeiros milímetros do solo (Benvenuti, 1995).

No presente trabalho foi estudada a emergência de plântulas de erva-de-touro, em função da profundidade de semeadura, do conteúdo de argila no substrato e do tratamento de sementes para a superação da necessidade de luz.

\section{MATERIAL E MÉTODOS}

Foram realizados dois experimentos no Departamento de Agricultura da UFLA, no Laboratório de Análise de Sementes e em casa de vegetação.

Os aquênios da erva-de-touro (Tridax procumbens L. - Asteraceae) foram coletados em plantas cultivadas em canteiros, no município de Lavras, MG, a partir de sementes de uma população há vários anos infestando culturas de soja e milho no município de Rondonópolis-MT. Os capítulos foram colhidos quando havia pelo menos um aquênio com papilho aberto e deixados secar à sombra para facilitar o desprendimento dos frutos. Após a retirada dos capítulos, os aquênios passaram por uma seleção visual, descartando-se os provenientes de flores femininas e aqueles com evidência de não possuírem sementes (de coloração branca) ou com sementes mal formadas.

No primeiro experimento, foi estudada a emergência das plântulas de erva-de-touro a 
partir de aquênios semeados nas profundidades de 1, 2, 3, 4, 5 e $6 \mathrm{~cm}$, incluindo-se também um tratamento com aquênios parcialmente enterrados, na posição vertical, até a região de inserção do papilho (APE). O experimento foi realizado em casa de vegetação, em vasos plásticos com dois litros de capacidade, preenchidos com substrato de solo contendo 60\% de argila. Foram utilizados aquênios com um mês após a coleta, realizada em outubro de 1997, armazenados em condições não-controladas (sala de laboratório). O umedecimento do substrato foi feito por subirrigação, mantendo-se pratos, sob os vasos perfurados, sempre cheios de água. Os tratamentos foram dispostos no delineamento inteiramente casualizado, com quatro repetições, com 100 aquênios por parcela. $\mathrm{O}$ número de plântulas emersas foi contado diariamente até 35 dias após a semeadura, e com base nesses dados foram calculados a emergência acumulada, a emergência final e o indice de velocidade de emergência (Maguire, 1962).

Após o período experimental (35 dias), foi avaliada a emergência de novas plântulas, em função da aplicação de $2 \mathrm{~g}$ de $\mathrm{KNO}_{3}$ na superfície de cada vaso ou da exposição das sementes à luz, pela retirada e/ou revolvimento da parte superior do substrato.

Para a caracterização do lote de sementes foram realizados testes de germinação em caixas plásticas tipo "gerbox", entre duas folhas de papel mata-borrão, em câmaras a $30{ }^{\circ} \mathrm{C}$ com 12 horas diárias de luz (G-EP30) e em casa de vegetação (G-EP), fazendo-se o reumedecimento do substrato sempre que necessário. Em casa de vegetação, avaliou-se também a germinação imergindo as sementes diretamente na água (130 ml), dentro das caixas tipo "gerbox (G-A). Foram utilizadas quatro repetições de 100 sementes em cada teste. O número de sementes germinadas (radícula visível) foi contado diariamente até 35 dias, e com base nesses dados foram calculados a germinação acumulada, a germinação final e o índice de velocidade de germinação (Maguire, 1962).

A temperatura ambiente na casa de vegetação variou de 20 a $36{ }^{\circ} \mathrm{C}$. Nos dias e horas mais quentes, atingiu $42{ }^{\circ} \mathrm{C}$ dentro dos vasos (nos primeiros $3 \mathrm{~cm}$ do substrato) e, dentro das caixas "gerbox", $46{ }^{\circ} \mathrm{C}$ entre as duas folhas de papel mata-borrão e $49{ }^{\circ} \mathrm{C}$ dentro da água.
No segundo experimento, a emergência de plântulas de erva-de-touro foi avaliada em função da utilização de sementes com e sem pré-tratamento para a superação da necessidade de luz, semeadas em areia a $3 \mathrm{~cm}$ de profundidade, e em substrato de solo, com 30 e $60 \%$ de argila, a $1 \mathrm{~cm}, 2 \mathrm{~cm}$ e APE. Esse prétratamento para a superação da necessidade de luz constou da embebição das sementes em solução de ácido giberélico $\left(\mathrm{GA}_{3}\right) 1 \mathrm{mmol} \mathrm{L}^{-1}+$ nitrato de potássio $\left(\mathrm{KNO}_{3}\right) 25 \mathrm{mmol} \mathrm{L}^{-1}$, durante 48 horas, entre duas folhas de papel mataborrão, em câmaras de germinação a $30^{\circ} \mathrm{C}$, com dois ciclos de 12 horas de luz branca. Os aquênios foram colhidos em dezembro de 1998, de uma única planta, embalados em sacos de papel e utilizados após 10 meses de armazenamento em ambiente de sala. A germinação das sementes, com e sem pré-tratamento, foi avaliada em câmaras de germinação a $30^{\circ} \mathrm{C}$, entre-papel, na presença (12 h/d) e ausência de luz. Os demais procedimentos experimentais foram os mesmos descritos para o primeiro experimento.

Os resultados foram submetidos à análise de variância e a comparação de médias foi realizada pelo teste de Scott e Knott a 5\% de probabilidade.

\section{RESULTADOS E DISCUSSÃO}

Os resultados obtidos no experimento 1 estão apresentados na Figura 1.

O lote de sementes utilizado apresentou $95,8 \%$ de germinação em câmaras a $30^{\circ} \mathrm{C}$ (Figura 1b), com índice de velocidade de germinação de 16,1 (Figura 1c), indicativos de boa qualidade. Nos vasos, houve $93,8 \%$ de emergência quando os aquênios foram parcialmente enterrados (Figura 1b), de forma mais rápida e uniforme do que a germinação em câmaras (Figura 1a, c), o que pode ser atribuído, entre outros fatores, a um melhor contato dos aquênios com o substrato úmido e à presença, na solução do solo, de substâncias como o nitrato, que interagem positivamente com a luz (Karssen \& Bouwmeester, 1992; Hilhorst et al., 1996). Entretanto, quando os aquênios foram colocados a 1,2 e $3 \mathrm{~cm}$ de profundidade, a emergência foi reduzida para valores entre 1,0 e $2,8 \%$, sendo nula a 4,5 e $6 \mathrm{~cm}$. Esses resultados são coerentes com a necessidade de luz 
para a germinação das sementes de erva-detouro, uma vez que os comprimentos de onda para ativação do processo germinativo só penetram nos primeiros milímetros do solo (Benvenuti, 1995). As emergências verificadas entre 1 e $3 \mathrm{~cm}$ seriam originadas de parte da população das sementes capazes de germinar na ausência de luz. Corroborando esses resultados, em sementes fotoblásticas positivas de Stachytarpheta cayennensis, Dias Filho (1996) também observou emergência de plântulas somente quando os diásporos foram colocados na superfície do solo.

Por outro lado, no trabalho de Sharma (1987), embora tenha havido maior emergência de plântulas de erva-de-touro quando as sementes foram colocadas na superfície do solo, estas ocorreram em profundidades de até $5 \mathrm{~cm}$, e a 1 e a $2 \mathrm{~cm}$ foram superiores à porcentagem

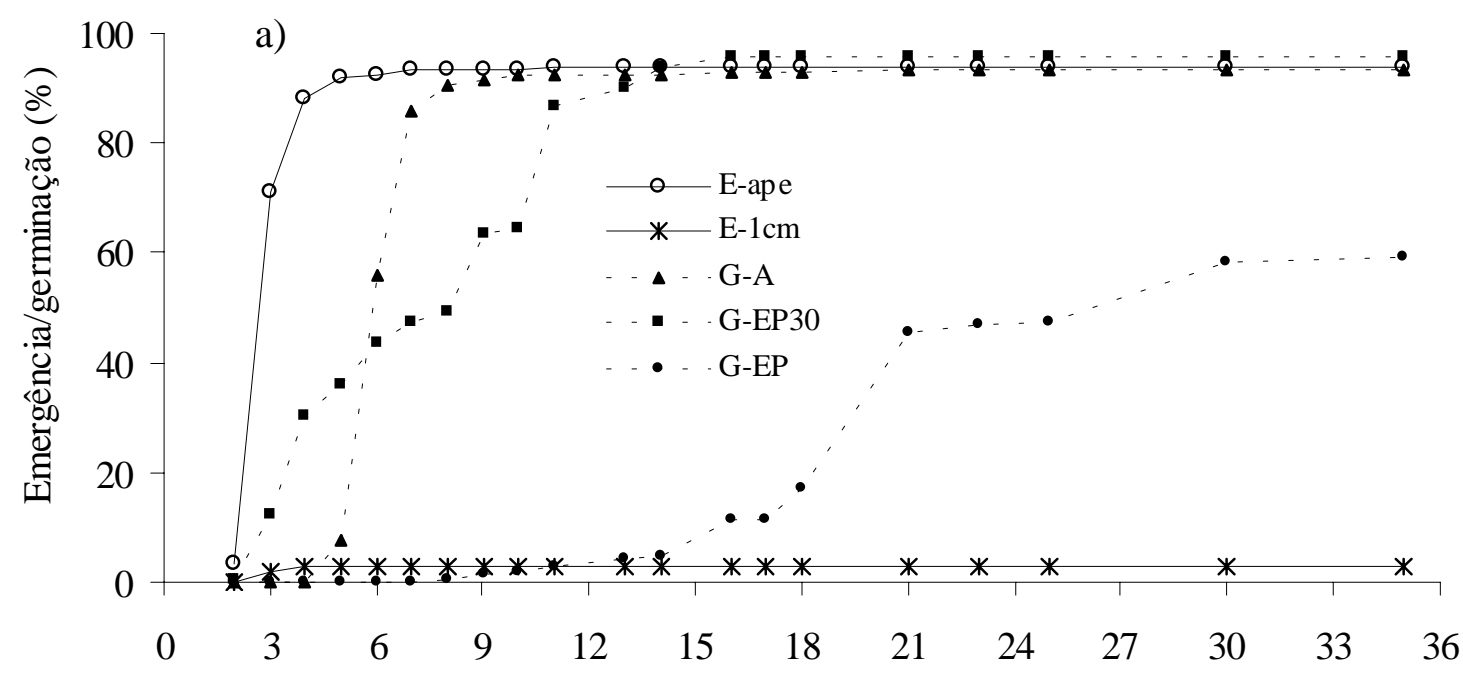

Dias após o início da embebição
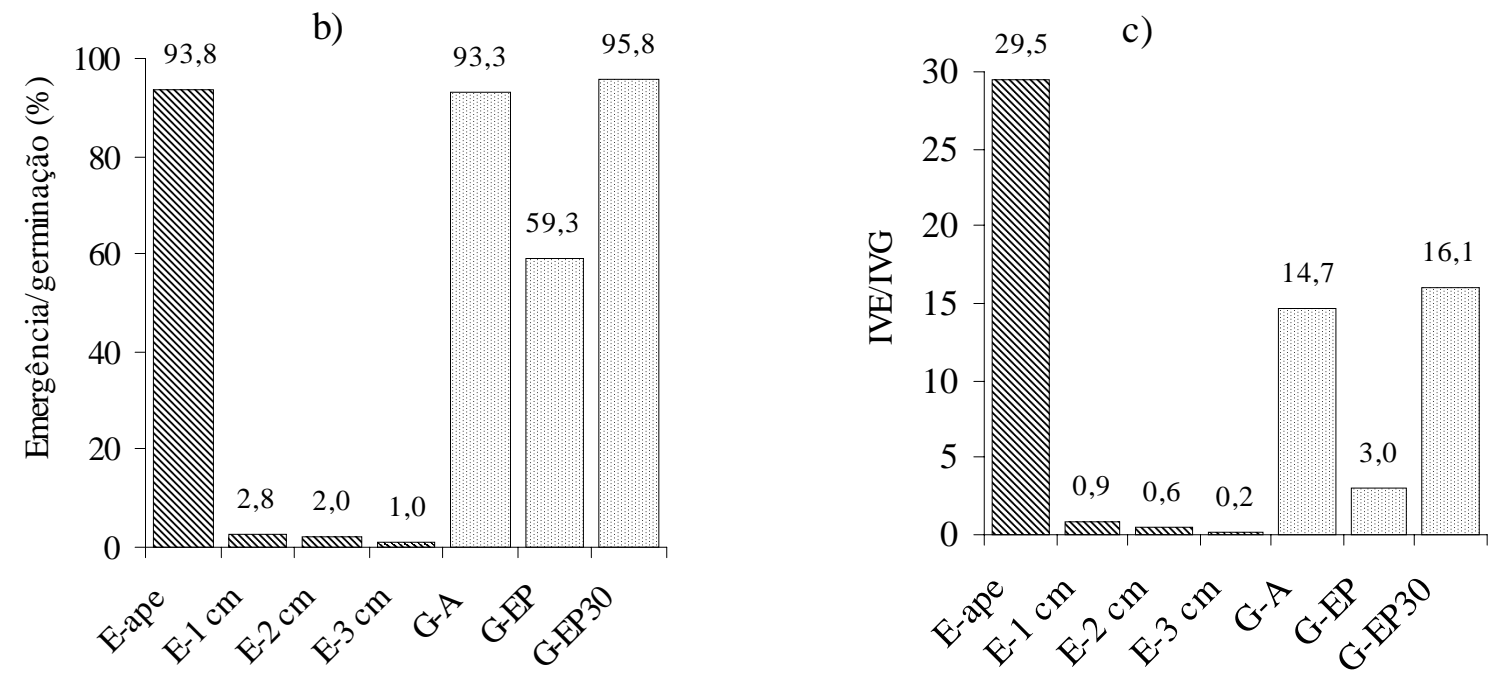

Figura 1 - Emergência acumulada (a), emergência final (b) e índice de velocidade de emergência (IVE) (c), em função da colocação dos aquênios da erva-de-touro parcialmente enterrados (E-ape), a $1 \mathrm{~cm}(\mathrm{E}-1 \mathrm{~cm})$, a $2 \mathrm{~cm}(\mathrm{E}-2 \mathrm{~cm})$ e a $3 \mathrm{~cm}(\mathrm{E}-3 \mathrm{~cm})$ de profundidade, em casa de vegetação. Adicionalmente, a germinação e o índice de velocidade de germinação das sementes (IVG) em água (G-A) e entre-papel (G-EP), dentro de casa de vegetação, e também em câmaras incubadoras a $30{ }^{\circ} \mathrm{C}(\mathrm{G}-\mathrm{EP} 30)$. UFLA, Lavras-MG, 2000. 
de germinação das sementes no escuro. Embora seja possível especular sobre a ação de compostos existentes no solo, como o nitrato, estimulando a germinação no escuro (Karssen \& Bouwmeester, 1992; Hilhorst et al., 1996), é surpreendente a ocorrência de emergências com semeaduras a $5 \mathrm{~cm}$ de profundidade em aquênios pequenos, que no estudo citado tinham massa de $0,8 \mathrm{mg}$.

Na presente pesquisa, a adição de $2 \mathrm{~g}$ de $\mathrm{KNO}_{3}$ por vaso, 35 dias após o início da embebição, não propiciou a emergência de novas plântulas, as quais foram observadas quando as sementes foram expostas à luz, pela retirada e/ ou revolvimento da parte superior do substrato.

Em casa de vegetação, a germinação das sementes em caixas plásticas foi maior quando as sementes foram imersas em água do que quando colocadas entre papel (Figura 1b). Esse resultado é coerente com a informação de Attridge (1990), de que a água atua filtrando mais eficientemente os comprimentos de ondas mais longos da luz, gerando um fotoequilíbrio mais favorável à conversão do fitocromo à forma ativada, e também em razão do efeito atenuador da luz causado pelo papel mata-borrão (Brasil, 1992). Adicionalmente, acreditase também que, quando entre-papel, o umedecimento das sementes pode ter sido deficiente, porque nas horas mais quentes do dia ocorria evaporação de grande parte da água contida no papel, a qual se condensava nas paredes internas das caixas (a temperatura interna na caixa era geralmente superior a $43^{\circ} \mathrm{C}$ ). Por esses resultados e hipóteses explicativas, pode-se também conjecturar que a menor velocidade de germinação verificada em câmaras tipo BOD, em temperaturas supraótimas (Guimarães et al., 2000b) ou em temperaturas alternadas (Guimarães et al., 2000c), seja o efeito de interações entre temperatura, umidade e luz, uma vez que em casa de vegetação, com temperaturas elevadas e alternadas, a emergência em vasos foi alta e rápida quando os aquênios foram parcialmente enterrados.

Os resultados obtidos no segundo experimento estão apresentados nas Tabelas 1 e 2 . A germinação das sementes utilizadas nesse experimento $\left(30{ }^{\circ} \mathrm{C}\right.$, entre-papel) foi de $84,8 \%$ na presença de luz (12 h/d) e de 5,0\% no escuro. A germinação no escuro elevou-se para $14,5 \%$ quando a embebição foi realizada em
$\mathrm{GA}_{3}+\mathrm{KNO}_{3}$ e para $55,5 \%$ quando as sementes foram submetidas ao pré-tratamento com $\mathrm{GA}_{3}+\mathrm{KNO}_{3}+\mathrm{luz}$.

Tabela 1 - Porcentagem de emergência de plântulas de erva-de-touro em função de profundidades de semeadura e pré-tratamento das sementes com ácido giberélico $\left(\mathrm{GA}_{3}\right)$ + nitrato de potássio $\left(\mathrm{KNO}_{3}\right)+$ luz. UFLA, Lavras-MG, 2000

\begin{tabular}{|c|c|r|r|}
\hline \multirow{2}{*}{$\begin{array}{c}\text { Pré-tratamento } \\
\text { com } \begin{array}{c}\mathrm{GA}_{3}+\mathrm{KNO}_{3} \\
+ \text { luz }\end{array}\end{array}$} & $\begin{array}{c}\text { aquênios } \\
\text { parcialmente } \\
\text { enterrados }\end{array}$ & $1 \mathrm{~cm}$ & $2 \mathrm{~cm}$ \\
\hline com & $66,4 \mathrm{~A} \mathrm{a}$ & $25,1 \mathrm{~A} \mathrm{~b}$ & $16,5 \mathrm{~A} \mathrm{c}$ \\
sem & $67,5 \mathrm{~A} \mathrm{a}$ & $2,1 \mathrm{~B} \mathrm{~b}$ & $0,1 \mathrm{~B} \mathrm{~b}$ \\
\hline
\end{tabular}

Médias seguidas por letras iguais, maiúsculas nas colunas e minúsculas nas linhas, são estatisticamente semelhantes (Scott e Knott 5\%).

Tabela 2 - Índice de velocidade de emergência de plântulas de erva-de-touro em função de profundidades de semeadura e pré-tratamento das sementes com ácido giberélico $\left(\mathrm{GA}_{3}\right)+$ nitrato de potássio $\left(\mathrm{KNO}_{3}\right)+$ luz. UFLA, Lavras-MG, 2000

\begin{tabular}{|c|c|c|c|}
\hline $\begin{array}{c}\text { Pré-tratamento } \\
\text { com } \begin{array}{c}\mathrm{GA}_{3}+\mathrm{KNO}_{3} \\
+ \text { luz }\end{array}\end{array}$ & $\begin{array}{c}|c| \\
\text { aquênios } \\
\text { parcialmente } \\
\text { enterrados }\end{array}$ & $1 \mathrm{~cm}$ & $2 \mathrm{~cm}$ \\
\hline com & $21,8 \mathrm{~A} \mathrm{a}$ & $6,5 \mathrm{~A} \mathrm{~b}$ & $3,5 \mathrm{~A} \mathrm{c}$ \\
sem & $13,6 \mathrm{~B} \mathrm{a}$ & $0,4 \mathrm{~B} \mathrm{~b}$ & $0,1 \mathrm{~B} \mathrm{~b}$ \\
\hline
\end{tabular}

Médias seguidas por letras iguais, maiúsculas nas colunas e minúsculas nas linhas, são estatisticamente semelhantes (Scott e Knott $5 \%$ ).

A emergência das plântulas de erva-detouro, em diferentes profundidades de semeadura, não foi influenciada pelo conteúdo de argila no substrato ( $>0,05)$, tendo sido alterada pelo pré-tratamento das sementes com $\mathrm{GA}_{3}+\mathrm{KNO}_{3}+\mathrm{luz}(\mathrm{p}<0,05)$. Quando os aquênios foram parcialmente enterrados, a emergência de plântulas foi semelhante para sementes tratadas e não-tratadas (Tabela 1), com média de $67,0 \%$. Nas profundidades de 1 e $2 \mathrm{~cm}$ essa variável foi reduzida para, respectivamente, 2,1 e $0,1 \%$ em sementes não-tratadas e 25,1 e $16,5 \%$ em sementes pré-tratadas.

Conforme discutido anteriormente, as plântulas de erva-de-touro originadas de 
sementes posicionadas em profundidades iguais ou superiores a $1 \mathrm{~cm}$ representariam parte da população dessas sementes capazes de germinar na ausência de luz. Essa hipótese foi confirmada nesse experimento, no qual o pré-tratamento para superação da necessidade de luz, eficiente para parte do lote de sementes, aumentou as emergências a 1 e a $2 \mathrm{~cm}$ de profundidade.

Em substrato de areia, a $3 \mathrm{~cm}$ de profundidade, não houve emergências (dados não apresentados), mesmo em sementes prétratadas, indicando a ocorrência de limitações de outra natureza.

A germinação mais rápida em sementes pré-tratadas, quando os aquênios foram parcialmente enterrados (Tabela 2), pode ser atribuída ao processo adiantado de germinação dessas quando colocadas nos vasos (após 48 horas de embebição), e também à interação positiva entre luz e $\mathrm{GA}_{3}+\mathrm{KNO}_{3}$ (Guimarães et al., 1999).

Uma das funções ecológicas do fotocontrole é evitar a germinação de sementes pequenas, como as de erva-de-touro, em profundidades inadequadas no solo, porque as reservas disponíveis nas plântulas não seriam suficientes para permitir-lhes crescer até a superfície, onde receberiam luz solar e passariam à condição autotrófica (Mayer \& PoljakoffMayber, 1989; Bewley \& Black, 1994). Na área de plantas daninhas, o conhecimento dessa informação pode ajudar na formulação de táticas de manejo, utilizando-se mais eficientemente o preparo do solo na redução do banco de sementes e/ou na diminuição da densidade de infestações iniciais. Como exemplo, preparos superficiais podem estimular a germinação das sementes (Dyer, 1995), que é considerado o principal fator responsável pela depleção no banco de sementes do solo (Karssen \& Bouwmeester, 1992), e o preparo profundo, com inversão de leiva, como ocorre com arado de aiveca, pode enterrar profundamente as sementes, prevenindo a germinação (Dyer, 1995).

\section{AGRADECIMENTOS}

A Cibele Carneiro Fernandes Guimarães e Rodrigo da Cunha Serpa, pelo auxílio na montagem e condução dos experimentos.

\section{LITERATURA CITADA}

ATTRIDGE, T. H. Light and plant responses. London: Edward Arnold, 1990. 148 p.

BENVENUTI, S. Soil light penetration and dormancy of jinsonweed (Datura stramonium) seeds. Weed Sci., v. 43, n. 3, p. 389-393, 1995.

BEWLEY, J. D.; BLACK, M. Seeds: physiology of development and germination. 2.ed. New York: Plenum, 1994. $445 \mathrm{p}$.

BRASIL. Ministério da Agricultura e Reforma Agrária. Regras para análise de sementes. Brasília: AGIPLAN, 1992. 365 p.

CARMONA, R. Problemática e manejo de bancos de sementes de invasoras em solos agrícolas. Planta Daninha, v. 10, n. $1 / 2$, p. $5-16,1992$.

DIAS FILHO, M. B. Germination and emergence of Stachytarpheta cayennensis and Ipomoea asarifolia. Planta Daninha, v. 14, n. 2, p. 118-126, 1996.

DYER, W. E. Exploiting weed seed dormancy and germination requirements through agronomic practices. Weed Sci., v. 43, n. 3, p. 498-503, 1995.

FERNÁNDEZ, O. A. Manejo integrado de malezas. Planta Daninha, v. 5, n. 2, p. 69-79, 1982.

GUIMARÃES, S. C.; SOUZA, I. F.; PINHO, E. V. R. V. Comportamento germinativo de sementes da erva-de-touro (Tridax procumbens L. - Asteraceæ): efeito da restrição hídrica e da luz. Inf. ABRATES, v. 9, n. 1/2, p. 94, 1999.

GUIMARÃES, S. C.; SOUZA, I. F.; PINHO, E. V. R. V. Desenvolvimento da planta de erva-de-touro (Tridax procumbens L.). In: CONGRESSO BRASILEIRO DA CIÊNCIA DAS PLANTAS DANINHAS, 22., 2000, Foz do Iguaçu. Resumos... Foz do Iguaçu: SBCPD, 2000a. p. 42.

GUIMARÃES, S. C.; SOUZA, I. F.; PINHO, E. V. R. V. Efeito de temperaturas sobre a germinação de sementes de erva-de-touro (Tridax procumbens). Planta Daninha, v. 18, n. 3, p. 457-464, 2000 b.

GUIMARÃES, S. C. et al. Efeito de temperaturas alternadas na germinação de sementes de erva-de-touro. In: CONGRESSO BRASILEIRO DA CIÊNCIA DAS PLANTAS DANINHAS, 22., 2000, Foz do Iguaçu. Resumos... Foz do Iguaçu: SBCPD, 2000c. p. 46.

HILHORST, H. W. M.; DERKX, M.P. M.; KARSSEN, C. M. An integrating model for seed dormancy cycling: characterization of reversible sensitivity. In: LANG, G. A. (Ed.). Plant dormancy: physiology, biochemistry and molecular biology. Wallingford: CAB International, 1996. p. 341-360. 
HOLZNER, W.; HAYASHI, I.; GLAUNINGER, J.

Reproductive strategy of annual agrestals. In: HOLZNER, W.; NUMATA, M. (Eds). Biology and ecology of weeds. The Hague: Dr W. Junk Publishers, 1982. p. 111-121.

KARSSEN, C. M.; BOUWMEESTER, H. J. Annual dormancy patterns of weed seeds influence weed control. In: INTERNATIONAL WEED CONTROL CONGRESS, 1., 1992, Melbourne. Proceedings... Melbourne: Weed Science Society of Victoria, 1992. p. 98-104.

MAGUIRE, J. D. Speed of germination-aid in relation evaluation for seedling emergence vigor. Crop Sci., v. 2, n. 2, p. 176-177, 1962.

MARKS, M. K.; AKOSIM, C. Achene dimorphism and germination in three composite weeds. Trop. Agric., v. 61, n. 1, p. 69-73, 1984.
MAYER, A. M.; POLJAKOFF-MAYBER, A. The germination of seeds. 4.ed. Oxford: Pergamon Press, 1989. $270 \mathrm{p}$.

POPAY, A. I. Investigations into the behaviour of the seeds of some tropical weeds. I. Laboratory germination tests. East Afr. agric. For. J., v. 39, n. 1, p. 31-43, 1974.

SHARMA, B. M. Preliminary ecological studies on lithophytes and chasmophytes in South-West Nigeria. Malaysian For., v. 50, n. 4, p. 391-402, 1987.

TOLEDO, R. E. B.; KUVA, M. A.; ALVES, P. L. C. A. Fatores que afetam a germinação e a emergência de Xanthium strumarium L.: dormência, qualidade da luz e profundidade de semeadura. Planta Daninha, v. 11, n. 1/2, p. $1520,1993$. 